\section{Fluorescein angiography-guided indocyanine green angiography for the detection of feeder vessels in subfoveal choroidal neovascularization}

Department of

Ophthalmology

University of Tokyo School of Medicine Tokyo, Japan

Correspondence:

Dr Yasuo Yanagi

Department of Regenerative

Medicine

Research Institute

International Medical

Center of Japan

1-21-1 Toyama

Shinjuku-ku

Tokyo 162-8655, Japan

Tel: + 81332027181

Ext.2727

Fax: +8133202 7192

E-mail: yanagi-tky@

umin.ac.jp

Received: 24 September 2002

Accepted: 21 March 2003

Proprietary interest: None.

\section{Abstract}

Aims To compare the newly devised fluorescein angiography (FA) - guided indocyanine green angiography (ICGA) with conventional ICGA for detecting feeder vessels in subfoveal choroidal neovascularization (CNV).

Methods The detection of feeder vessels was attempted in 86 AMD patients with subfoveal CNV: 44 (age $70.4 \pm 4.5$ years) underwent conventional ICGA (control group) and 42 (age $70.9 \pm 4.0$ years) underwent an FAguided ICGA (FA-guided group) using a double-detector scanning laser ophthalmoscope (SLO). In the control group, indocyanine green (ICG) was injected simultaneously with fluorescein. The patients were instructed to gaze forward localizing the fovea at the centre. In the FA-guided group, fluorescein sodium was injected a few minutes prior to ICG, and the patients were instructed to fixate in the appropriate direction by referring to the ongoing FA on the monitoring screen. In both groups, a $20^{\circ}$ visual angle was used to capture good images of feeder vessels in ICGA and, in case ICGA missed the first images of the entire CNV filling, an additional injection of ICG was given in the late phase to record the choroidal filling again. The overall detection rate, singleinjection detection rate, double-injection rate and examination time were analysed using Fisher's direct exact probability test or MannWhitney's U-test.

Results There was no significant difference in the overall detection of feeder vessels between the two groups $(50 \%$ in the control group and $52.3 \%$ in the FA-guided group; $\boldsymbol{P}=0.49$ with Fisher's direct exact probability test). However, in the FA-guided group, the single injection detection rate was significantly higher (45.1 and $\mathbf{1 5 . 9 \%}$, respectively; $P<0.001$ with Fisher's direct exact probability test); significantly less double injections were required (7.1 and $50 \%$, respectively; $P=0.003$ with Fisher's direct exact probability test); and significantly shorter examination times were needed $(9.6 \pm 3.7$ and $14.1 \pm 6.8 \mathrm{~min}$, respectively; $\boldsymbol{P}=\mathbf{0 . 0 2}$ with Mann-Whitney's $U$-test). Conclusion FA-guided ICGA is effective for detecting feeder vessels of subfoveal CNV, minimizing the amount of ICG injected and the examination time compared to conventional ICGA.

Eye (2004) 18, 474-477. doi:10.1038/sj.eye.6700707

Keywords: fluorescein angiography; indocyanine green angiography; choroidal neovascularization and feeder vessel

Introduction

Exudative age-related macular degeneration (AMD) is a major cause of legal blindness in developed countries. Photocoagulation of the entire choroidal neovascularization $(\mathrm{CNV})$ is a treatment option for exudative AMD, with efficacy proved in large randomized control studies performed by the Macular Photocoagulation Study Group. ${ }^{1-3}$ However, most CNVs extend to the subfoveal lesion, 
and permanent central visual loss is inevitable immediately after the photocoagulation. The poor natural history of subfoveal CNV and the limitations of conventional photocoagulation therapies have prompted the search for alternative therapies, such as macular translocation surgery, ${ }^{4,5}$ radiation therapy, ${ }^{6-8}$ photodynamic therapy ${ }^{9}$ and feeder vessel photocoagulation therapy. ${ }^{10-12}$ Several investigators have reported favourable outcomes from feeder vessel photocoagulation. High-contrast indocyanine green videoangiography (ICGA) using a confocal scanning laser ophthalmoscope (SLO) with a high magnification ( $20^{\circ}$ visual angle) is best suited to the capture of images of feeder vessels. ${ }^{10-13}$ However, because of the narrow visual angle of SLO and the unpredictable localization of CNV together with the blurring of images due to involuntary eye movements of the patients, ICGA often misses images of CNV filling, which usually occurs in the early phase of the angiography, and fails to detect feeder vessels. In such cases, the ICGA landmark method $^{11}$ is sometimes helpful for acquiring images with an additional injection of indocyanine green (ICG), referring to the later stage ICGA image as a landmark. The ICGA landmark method requires more ICG and a longer examination time than usual angiographies. Although the adverse effects from ICG do not appear to be dose dependent and ICG is relatively safe in ophthalmological setting, ${ }^{14}$ the additional ICG may pose stress in the patients, since the adverse effect of ICG is considered to occur in a dose-dependent manner in cardiovascular examination. ${ }^{15}$ Simultaneous fluorescein angiography (FA) and ICGA on separate monitoring screens became possible with the advent of an SLO with a double detector system. ${ }^{16}$ To obtain images of feeder vessels in the early phase more efficiently, reduce the amount of ICG to be injected and shorten the examination time, we performed ICGA using FA as a landmark (FA-guided ICGA), taking advantage of this SLO with the double-detector system.

\section{Patients and methods}

A total of 86 consecutive cases of AMD with newly diagnosed subfoveal CNV classified according to the definition of the Macular Photocoagulation Study ${ }^{1}$ were recruited to the study from the outpatient clinic of Tokyo University Hospital between June 1999 and June 2001. FA and ICGA criteria for subfoveal CNV included evidence of leakage from $\mathrm{CNV}$, extending under the centre of the foveal avascular zone. Cases with polypoidal choroidal vasculopathy, diagnosed from the ICGA findings, were excluded from this study. Patients were randomly assigned to a control or FA-guided group. In all, 44 patients were examined with the conventional ICGA (control group) and 42 patients with FA-guided ICGA (FA-guided group) (Table 1).

\section{Control group}

For simultaneous FA and ICGA, the fovea was localized centre of the monitoring screen using infrared imaging with a $20^{\circ}$ visual angle and instructing the patients to

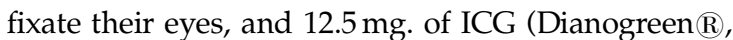
Daiichi pharmaceutical) diluted in $5 \mathrm{ml}$ of $10 \%$ fluorescein sodium (FLUORESCITE® injection, Alcon, Japan) was injected into the antecubital vein as a single bolus followed by a $5 \mathrm{ml}$ saline flush. FA and ICGA images were simultaneously recorded using the SLO (Rodenstock, Ottobrunn-Riermerling, Germany) at a $20^{\circ}$ visual angle in the early phase on digital videotape. After a few minutes, the images were captured at a $40^{\circ}$ visual angle to confirm the entire image of the CNV. Analysing the ICG angiograms recorded on the digital videotape by repeatedly viewing appropriate image segments, the feeder vessels were detected based on the dye filling of the choroidal vessels in the vicinity of the abnormal vessel growth. The diagnostic criteria of feeder vessels did not include umbrella configurations, in which filling occurs from the inside of the CNV. When ICGA missed the early phase of the filling, additional ICG was injected in the

Table 1 Summary of clinical characteristics of patients and comparison of feeder vessel detection in conventional method and FAguided ICGA method

\begin{tabular}{|c|c|c|c|}
\hline & Conventional method & FA-guided ICGA method & P-value \\
\hline$n$ & 44 & 42 & \\
\hline Age (mean $\pm S D$ years $)$ & $70.4 \pm 4.5$ & $70.9 \pm 4.0$ & a 0.67 \\
\hline Overall feeder vessel detection rate & $50 \%(22 / 44)$ & $52.4 \%(22 / 42)$ & b0.50 \\
\hline 'Rate of ICG double injection & $50 \%(22 / 44)$ & $7.1 \%(19 / 42)$ & ${ }^{\mathrm{b}}<0.0001$ \\
\hline${ }^{c}$ Feeder vessel detection rate in the first frame & $15.9 \%(7 / 44)$ & $45.2 \%(19 / 42)$ & ${ }^{\mathrm{b}} 0.003$ \\
\hline${ }^{\mathrm{c}}$ Total angiography time (mean $\left.\pm \mathrm{SD} \min \right)$ & $14.1 \pm 6.8$ & $9.6 \pm 3.7$ & b 0.02 \\
\hline${ }^{\mathrm{d}}$ Adverse effect & $6.8 \%(3 / 44)$ & $4.8 \%(2 / 42)$ & ${ }^{\mathrm{b}} 0.54$ \\
\hline
\end{tabular}

\footnotetext{
${ }^{a}$ Mann-Whitney's U-test.

${ }^{\text {b}}$ Fisher's dorect exact probability test.

'Significantly different from conventional method
}

${ }^{\mathrm{d}}$ Nausea and vomitting. 
later phase (usually about $25 \mathrm{~min}$ ) after the background fluorescence had decreased enough to gain high-contrast images. While the patients were instructed to fixate so that the entire CNV was located centre of the FA and ICGA monitoring screen, additional ICG (12.5 mg in $5 \mathrm{ml}$ saline) was injected to record the early ICGA images again.

\section{FA-guided group}

A volume of $5 \mathrm{ml}$ of $10 \%$ fluorescein sodium was injected into the antecubital vein as a single bolus, and FA images were recorded with a $40^{\circ}$ visual angle. At $2-3$ min after the injection of fluorescein sodium, the FA images were analysed on the monitoring screen and the entire $\mathrm{CNV}$ lesion or the lesion under which the $\mathrm{CNV}$ is suspected (the presumed CNV lesion can be detected by a 'notch sign' or 'oozing' in the FA) was located. Thereafter, the patients were instructed to fixate in an appropriate direction so that the CNV lesion could be located in the centre of the FA monitoring screen with a $20^{\circ}$ visual angle. Then, $12.5 \mathrm{mg}$ of ICG diluted in $5 \mathrm{ml}$ of saline was injected into the antecubital vein as a single bolus followed by a $5 \mathrm{ml}$ saline flush. The early-phase images were monitored with a $20^{\circ}$ visual angle on screen and recorded on a digital videotape. Keeping the CNV image at the centre of the screen of FA allows the initial ICG dye filling of the $\mathrm{CNV}$ to be recorded at the centre of the ICG monitoring screen (Figure 1). After a few minutes, the images were captured with a $40^{\circ}$ visual angle size to confirm the entire image of the CNV. Similar to the control group, the feeder vessels were detected based on the dye filling of the choroidal vessels in the vicinity of the abnormal vessel growth. In case ICGA missed the entire image of the CNV filling in the early phase, additional ICG was injected as described above to regain images of choroidal filling.

\section{Results}

There was no significant difference in age between the two groups (Table 1). There was no significant difference in the overall rate of detection of feeder vessels between the two groups (50\% in the control group and $52.3 \%$ in the FAguided group; $P=0.49$ with Fisher's direct exact probability test). The single injection detection rate was significantly higher in the FA-guided group (45.1\%) than the control group $(15.9 \% ; P<0.001$ with Fisher's direct exact probability test). The additional injection of ICG was significantly less required in the FA-guided group $(7.1 \%)$ than in the control group $(50 \% ; P=0.003$ with Fisher's direct exact probability test). The examination time was significantly shorter in the FA-guided group $(9.6 \pm 3.7 \mathrm{~min})$ than in the control group $(14.1 \pm 6.8 \mathrm{~min} ; P=0.02$ with Mann-Whitney's $U$-test). The frequency of complications was not significantly different between the two groups.
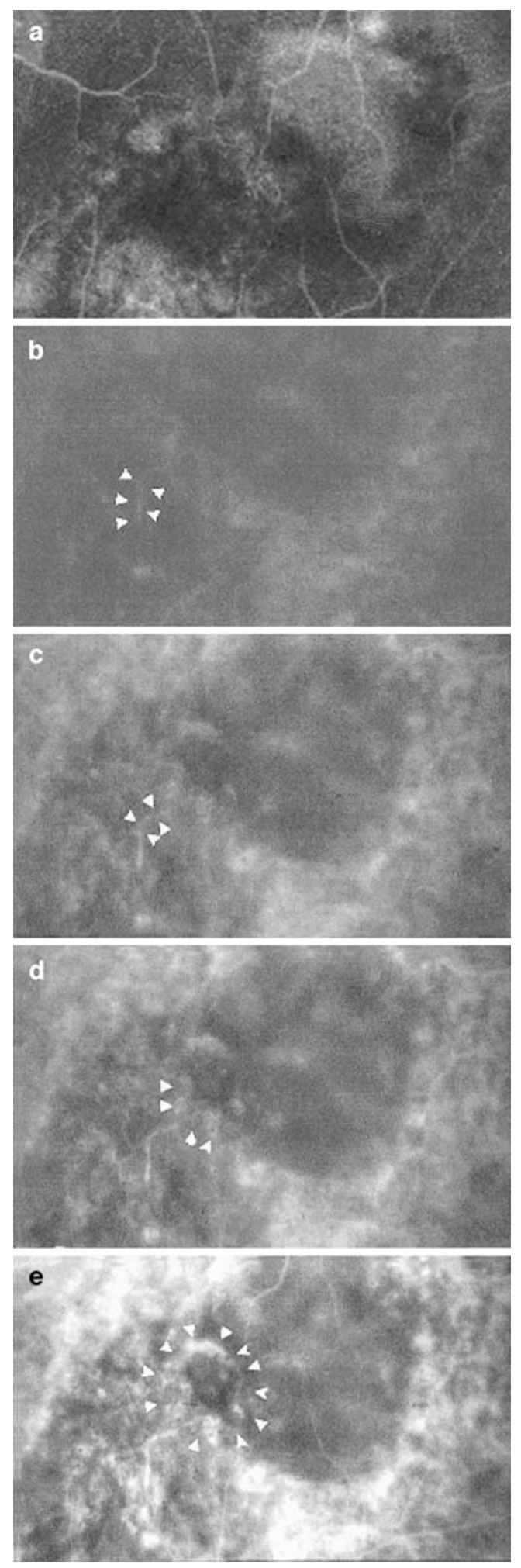

Figure 1 FA-guided ICGA. CNV is suspected to localize under the notch of the pigment epithelial detachment in the fluorescein angiogram (a). Confirming the CNV lesion is located at the centre of the FA monitoring screen, ICG is injected and ICGA is recorded with a $20^{\circ}$ visual angle (b-e; arrowheads indicate the feeder vessel and CNV). 


\section{Conclusion}

Our results show that the overall feeder vessel detection rate with the conventional ICGA landmark method (50\%) and FA-guided ICGA (52. 3\%) is comparable with the results of Shiraga et al $(22 \%),{ }^{11}$ Straurenghi $(86 \%)^{12}$ and Piermarocchi (22.4\%). ${ }^{17}$ Notably, using the FA-guided method, feeder vessel detection rate after a single ICG injection (45.2\%) was almost equal to the overall detection rate using conventional ICGA ( $50 \% ; P=0.47$ with Fisher's direct exact probability test). We failed to detect feeder vessels in the following cases: first, if the vascular meshwork of CNV was not apparent in the early phase and the entire CNV became apparent only in the late phase; second, if the entire CNV was filled

simultaneously or the filling started from the inside of the $\mathrm{CNV}$ presumably because the feeder vessel was under the $\mathrm{CNV}$; third, if the CNV was too large to capture an entire image of the filling on the monitoring screen at a $20^{\circ}$ angle. However, considering that feeder vessel photocoagulation therapy is effective for small CNV but has limited effect for large $\mathrm{CNV}^{11}$ it is important to detect feeder vessels in small CNV in current practice.

Although the adverse effects from ICG do not appear to be dose-dependent and ICG is relatively safe in an ophthalmological setting, ${ }^{14}$ adverse effects of ICG occur in a dose-dependent manner in a cardiovascular examination. ${ }^{14}$ Whether complications are less frequent with the FA-guided ICGA than the conventional method awaits further study; however, our results show that FAguided ICGA has advantages with respect to the amount of ICG injected and examination time. An alternative way to reduce injections of ICG is to use FA to localize the CNV lesion. Then, the lesion can be localized at a $20^{\circ}$ visual angle size in ICGA. However, the simultaneous injection of fluorescein sodium and ICG itself is not associated with an increase in the rate of complications and the advantage of simultaneous angiography has been well established. ${ }^{16}$ Thus, we believe that the FAguided method has advantages over the ICG landmark method and the method using FA as a landmark.

In conclusion, FA-guided ICGA is an effective method of detecting feeder vessels of subfoveal $\mathrm{CNV}$, requiring less ICG and time than conventional ICGA.

\section{References}

1 Macular Photocoagulation Study Group. Subfoveal neovascular lesions in age-related macular degeneration. Guidelines for evaluation and treatment in the macular photocoagulation study. Arch Ophthalmol 1991; 109: 1242-1257.

2 Macular Photocoagulation Study Group. Five-year followup of fellow eyes of patients with age-related macular degeneration and unilateral extrafoveal choroidal neovascularization. Arch Ophthalmol 1993; 111: 1189-1199.

3 Macular Photocoagulation Study Group. Five-year followup of fellow eyes of individuals with ocular histoplasmosis and unilateral extrafoveal or juxtafoveal choroidal neovascularization. Arch Ophthalmol 1996; 114: 677-688.

4 Cekic O, Ohji M, Hayashi A, Fujikado T, Tano Y. Foveal translocation surgery in age-related macular degeneration. Lancet 1999; 354: 340.

5 Lewis H, Kaiser PK, Lewis S, Estafanous M. Macular translocation for subfoveal choroidal neovascularization in age-related macular degeneration: a prospective study. Am J Ophthalmol 1999; 128: 135-146.

6 Ciulla TA, Danis RP, Chakravarthy U. Radiation therapy for exudative age-related macular degeneration. Retina 1998; 18: 387-389.

7 Finger PT, Berson A, Ng T, Szechter A. Ophthalmic plaque radiotherapy for age-related macular degeneration associated with subretinal neovascularization. Am J Ophthalmol 1999; 127: 170-177.

8 Hart PM, Chakravarthy U, MacKenzie G, Archer DB, Houston RF. Teletherapy for subfoveal choroidal neovascularisation of age-related macular degeneration: results of follow up in a non-randomised study. $\mathrm{Br} J$ Ophthalmol 1996; 80: 1046-1050.

9 Treatment of age-related macular degeneration with photodynamic therapy (TAP) Study Group. Photodynamic therapy of subfoveal choroidal neovascularization in agerelated macular degeneration with verteporfin: one-year results of 2 randomized clinical trials - TAP report. Arch Ophthalmol 1999; 117: 1329-1345.

10 Desatnik H, Treister G, Alhalel A et al. ICGA-guided laser photocoagulation of feeder vessels of choroidal neovascular membranes in age-related macular degeneration. Indocyanine green angiography. Retina 2000; 20: 143-150.

11 Shiraga F, Ojima Y, Matsuo T et al. Feeder vessel photocoagulation of subfoveal choroidal neovascularization secondary to age-related macular degeneration. Ophthalmology 1998; 105: 662-669.

12 Staurenghi G, Orzalesi N, La Capria et al. Laser treatment of feeder vessels in subfoveal choroidal neovascular membranes: a revisitation using dynamic indocyanine green angiography. Ophthalmology 1998; 105: 2297-2305.

13 Flower RW. Optimizing treatment of choroidal neovascularization feeder vessels associated with age-related macular photocoagulation. Am J Ophthalmol 2002; 134: 228-239.

14 Hope-Ross M, Yannuzzi LA, Gragoudas ES, Guyer DR, Slakter JS, Sorenson JA et al. Adverse reactions to indocyanine green. Ophthalmology 1994; 101: 529.

15 Speich RB, Hoffmann U et al. Anaphylactoid reactions after indocyanine-green administration. Ann Intern Med 1988; 109: 345-346.

16 Bischoff PM, Niederberger HJ, Torok B, Speiser P. Simultaneous indocyanine green and fluorescein angiography. Retina 1995; 15: 91-99.

17 Piemarocchi S, Guidice GL, Sartore M, Friede F, Segato T, Pilotto E et al. Photodynamic therapy increases the eligibility for feeder vessel treatment of choroidal neovascularization caused by age-related macular degeneration. Am J Ophthalmol 2002; 133: 572-575. 